\title{
Abriendo Oportunidades: Material didáctico para sesiones de trabajo
}

Population Council

Follow this and additional works at: https://knowledgecommons.popcouncil.org/departments_sbsr-pgy

Part of the Civic and Community Engagement Commons, Family, Life Course, and Society Commons, and the Gender Equity in Education Commons How does access to this work benefit you? Let us know!

\section{Recommended Citation}

"Abriendo Oportunidades: Material didáctico para sesiones de trabajo." Guatemala City: Population Council, 2018. 


\section{Derechos de las Mujeres, Jóvenes y Niñas indígenas}
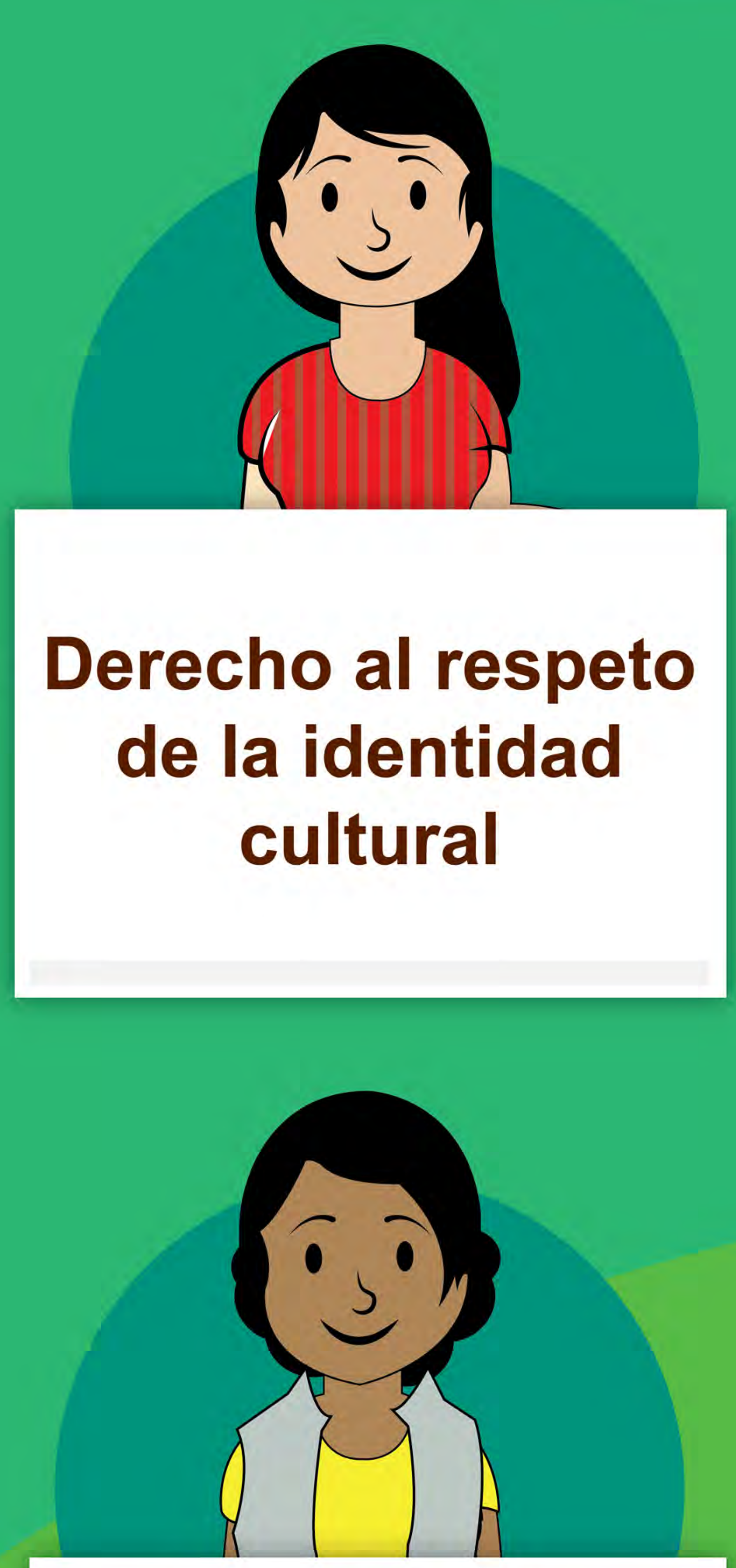

Derecho a la participación en cargos de dirección y toma de decisión a todo nivel.
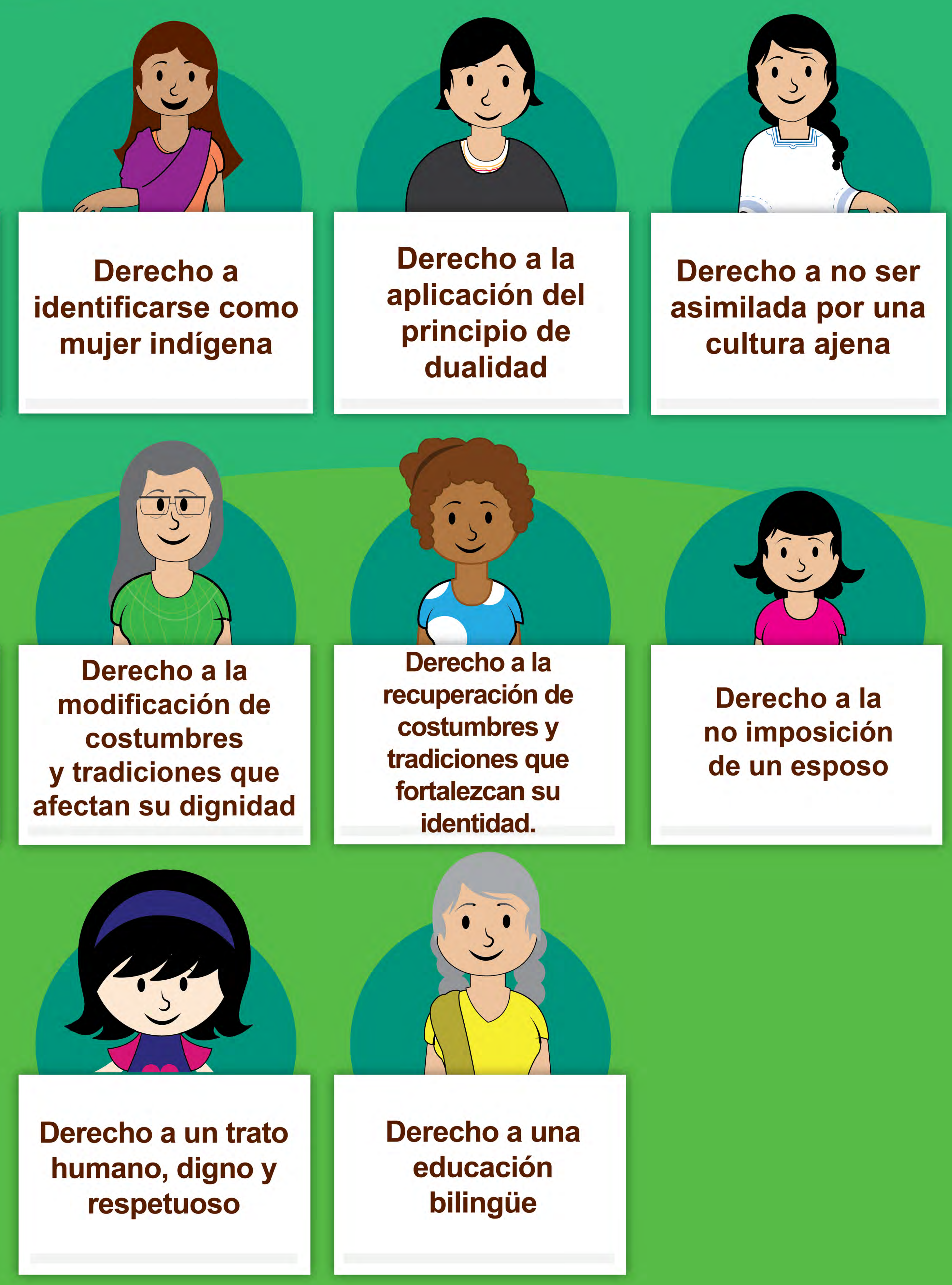

Derecho a no ser asimilada por una cultura ajena 


\section{Derechos de las niñas, los niños y adolescentes}

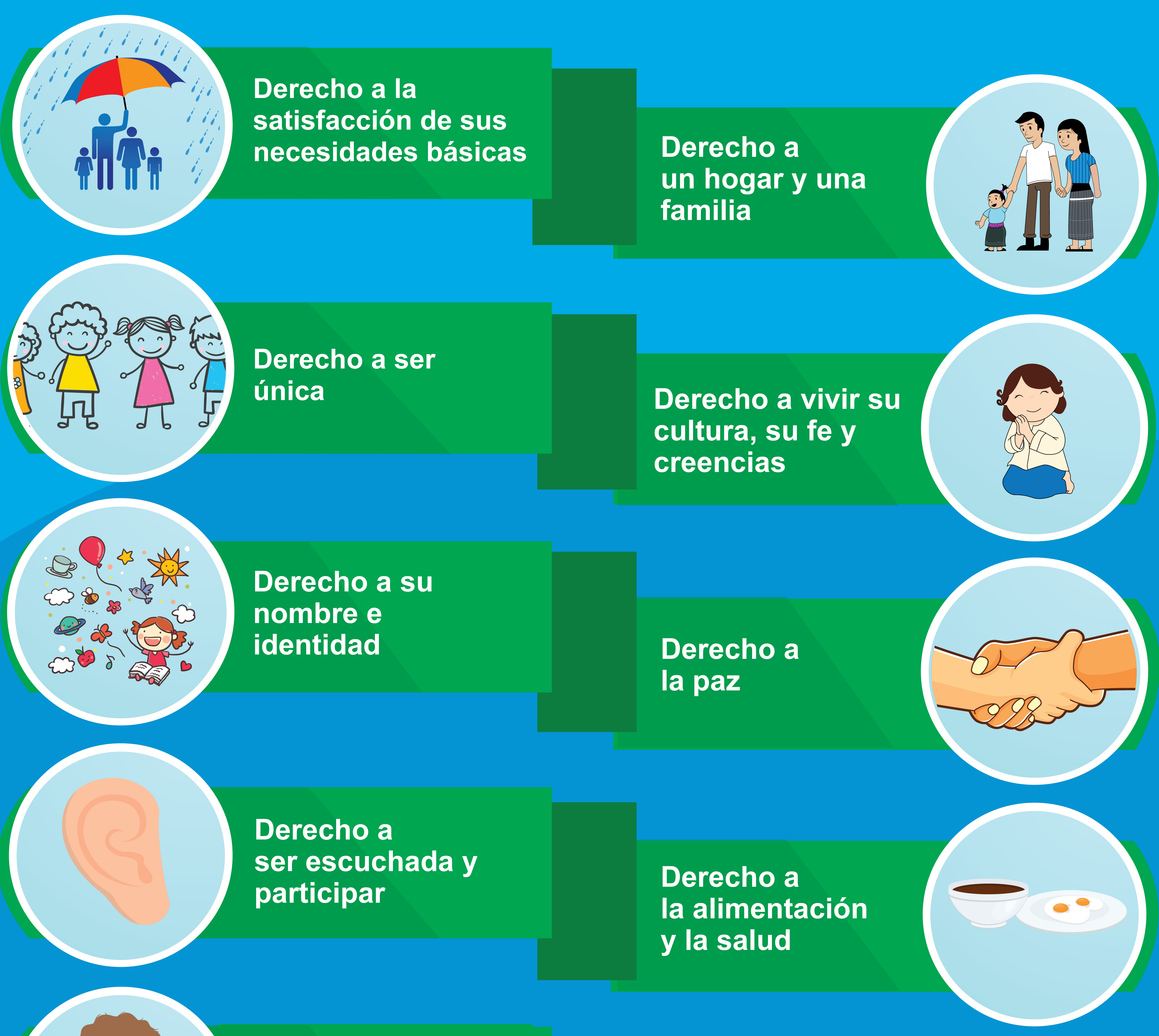

Derecho a su privacidad 


\section{Mapa de}

Guatemala

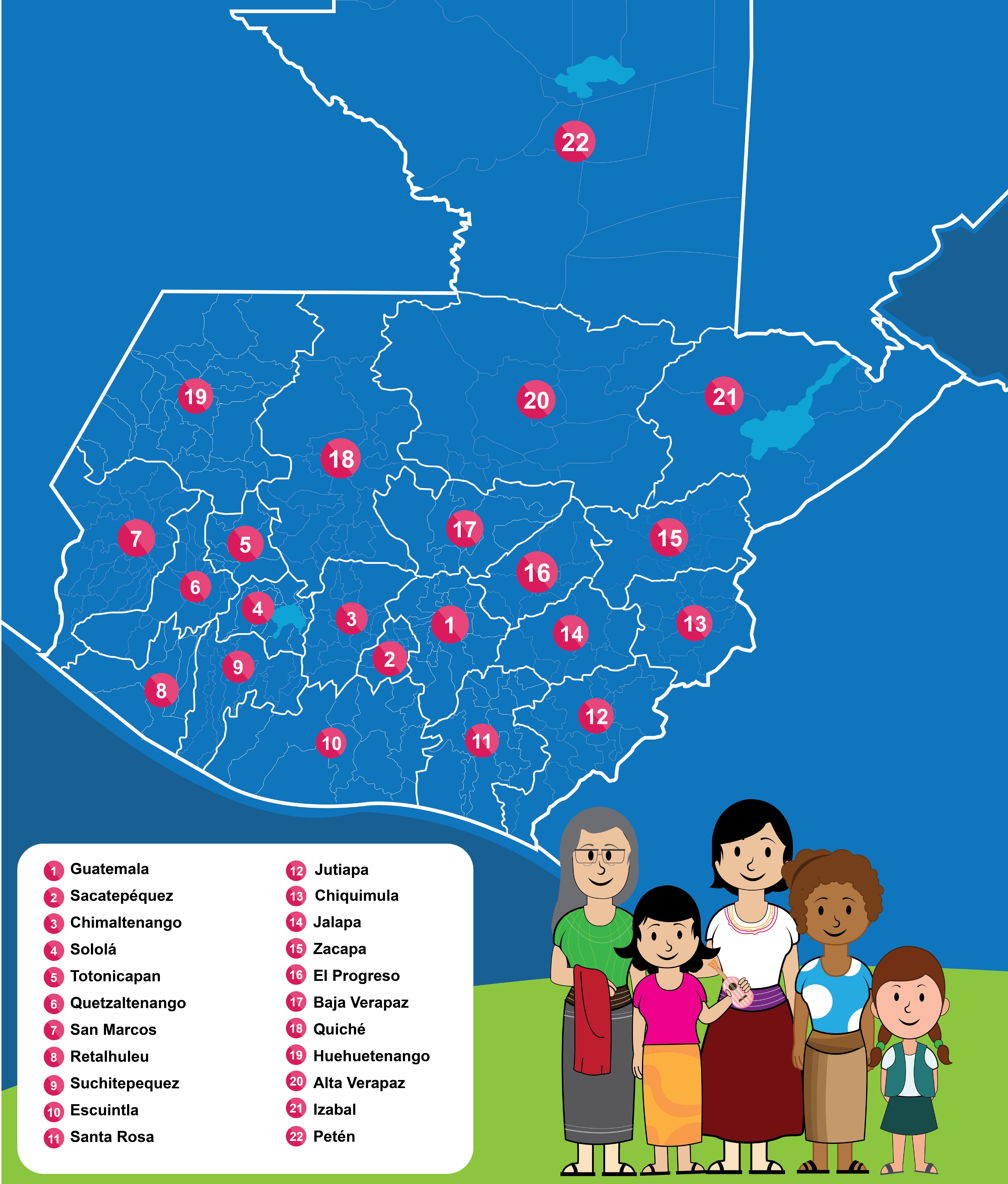

